\title{
BMP2 sensitizes glioblastoma stem-like cells to Temozolomide by affecting HIF-1 $\alpha$ stability and MGMT expression
}

\author{
L Persano ${ }^{*, 1,4}$, F Pistollato ${ }^{1,4}$, E Rampazzo ${ }^{1}$, A Della Puppa ${ }^{2}$, S Abbadi ${ }^{1}$, C Frasson ${ }^{1}$, F Volpin ${ }^{1}$, S Indraccolo ${ }^{3}$, R Scienza ${ }^{2}$ and \\ G Basso ${ }^{1}$
}

Glioblastoma multiforme (GBM) is the most common brain tumour, characterized by a central and partially necrotic (i.e., hypoxic) core enriched in cancer stem cells (CSCs). We previously showed that the most hypoxic and immature (i.e., CSCs) GBM cells were resistant to Temozolomide (TMZ) in vitro, owing to a particularly high expression of 06-methylguanine-DNAmethyltransferase (MGMT), the most important factor associated to therapy resistance in GBM. Bone morphogenetic proteins (BMPs), and in particular BMP2, are known to promote differentiation and growth inhibition in GBM cells. For this reason, we investigated whether a BMP2-based treatment would increase TMZ response in hypoxic drug-resistant GBM-derived cells. Here we show that BMP2 induced strong differentiation of GBM stem-like cells and subsequent addition of TMZ caused dramatic increase of apoptosis. Importantly, we correlated these effects to a BMP2-induced downregulation of both hypoxia-inducible factor-1 $\alpha$ (HIF-1 $\alpha$ ) and MGMT. We report here a novel mechanism involving the HIF-1 $\alpha$-dependent regulation of MGMT, highlighting the existence of a HIF-1 $\alpha /$ MGMT axis supporting GBM resistance to therapy. As confirmed from this evidence, overstabilization of HIF-1 $\alpha$ in TMZ-sensitive GBM cells abolished their responsiveness to it. In conclusion, we describe a HIF-1 $\alpha$ dependent regulation of MGMT and suggest that BMP2, by down-modulating the HIF-1 $\alpha$ /MGMT axis, should increase GBM responsiveness to chemotherapy, thus opening the way to the development of future strategies for GBM treatment.

Cell Death and Disease (2012) 3, e412; doi:10.1038/cddis.2012.153; published online 18 October 2012

Subject Category: Cancer

Glioblastoma multiforme (GBM) is a heterogeneous, highly proliferative brain tumour, currently treated by surgical intervention, followed by radio- and Temozolomide(TMZ)based chemotherapy. TMZ is an oral alkylating agent considered as a tolerable and effective drug for GBM tumour treatment. When $\mathrm{TMZ}$ is combined with radiotherapy in patients with newly diagnosed GBM, survival is significantly prolonged. ${ }^{1}$ Even though this finding has led to the widespread use of TMZ for GBM management, tumour recurrence and mortality rate of these patients still remains very high, raising concerns regarding its actual effectiveness. ${ }^{2,3} \mathrm{TMZ}$ achieves its cytotoxic effect mainly by methylating guanine residues in DNA at $\mathrm{O} 6$ position. This adduct can be removed by the DNA repair protein O6-methylguanine-DNA-methyltransferase (MGMT), which is heterogeneously expressed in GBM. Indeed, lack of MGMT expression due to a methylated MGMT promoter is considered a good prognostic factor in TMZ-treated GBM patients. ${ }^{4,5}$

The GBM cancer stem cell (CSC) population $\left(\mathrm{CD}_{133^{+}}\right)$is considered the most chemoresistant cell fraction in these tumours, in vitro and in vivo, and responsible for relapse. ${ }^{6,7}$ Controversial data indicate that $\mathrm{TMZ}$ seems to induce a doseand time-dependent decline of the GBM CSC population. ${ }^{8}$ Oppositely, other studies indicate that $T M Z$ is mainly ineffective on $\mathrm{CD}_{133^{+}}$GBM cells, which are characterized by high MGMT expression. ${ }^{2,3}$ These findings led to the still debated hypothesis that MGMT promoter methylation associated with negative MGMT protein expression may be a good prognostic factor in GBM patients. ${ }^{9-11}$

We recently demonstrated that GBM tumour mass, concentrically sampled by means of image guided surgery, is characterized by a central and partially necrotic core, with a high hypoxia-inducible factor- $1 \alpha$ (HIF-1 $\alpha$ ) expression, particularly enriched in $\mathrm{CD}_{133^{+}}$and $\mathrm{Nestin}^{+}$cells. On the contrary, the peripheral and more vascularized GBM tumour area is mainly characterized by more differentiated GFAP ${ }^{+}$ (glial acidic fibrillary protein) and $\beta$-III-tubulin ${ }^{+}$cells. ${ }^{3}$ Analogously, recent works have shown that CSCs reside in two niches within brain tumours, a peri-vascular location and the surrounding necrotic and/or less vascularized (i.e., hypoxic)

\footnotetext{
${ }^{1}$ Oncohematology Laboratory, Department of Woman and Child Health, University of Padova, Padova, Italy; ${ }^{2}$ Neurosurgery, Department of Neuroscience, University of Padova, Padova, Italy and ${ }^{3}$ Istituto Oncologico Veneto (IOV)-IRCCS, Padova, Italy

*Corresponding author: L Persano, Oncohematology Laboratory, Department of Woman and Child Health, University of Padova, Via Giustiniani 3, Padova 35128, Italy. Tel: +39 049 8211471; Fax: +39049 8211462; E-mail: luca.persano@unipd.it

${ }^{4}$ These authors contributed equally to this work.

Keywords: Glioblastoma; BMP2; temozolomide; hypoxia; HIF-1 $\alpha$; MGMT

Abbreviations: BMP, bone morphogenetic protein; ChIP, chromatin immunoprecipitation; CSCs, cancer stem cells; GBM, glioblastoma multiforme; GFAP, glial acidic fibrillary protein; GFP, green fluorescent protein; HIF, hypoxia-inducible factor; HRE, hypoxia-responsive element; MGMT, O6-methylguanine-DNA-methyltransferase; ODD domain, oxygen-dependent degradation domain; PHD2, proline hydroxylase 2; PI, propidium iodide; TMZ, Temozolomide

Received 03.8.12; revised 31.8.12; accepted 17.9.12; Edited by A Verkhratsky
} 
tissue. ${ }^{12-14}$ Moreover, we and the others recently reported that restricted oxygen conditions increase the CSC fraction, promoting acquisition of a stem-like state ${ }^{14-17}$ and suggest that multiple HIF-regulated genes are preferentially expressed in glioma stem cells in comparison to non-stem tumour cells and normal neural progenitors. ${ }^{18}$ Additionally, hypoxia is known to induce changes in the tumour biology and its microenvironment, leading to increased aggressiveness and resistance to chemotherapy and radiation. ${ }^{19}$ We previously found that $T M Z$ impacts tumour cell survival only in GBM cells derived from the peripheral layer of the tumour mass, being ineffective in cells derived from the core and from the intermediate hypoxic layer. ${ }^{3}$ Hence, there is a critical need to develop novel therapeutic approaches in order to target glioma cells from the hypoxic core.

A number of studies reported on the role of bone morphogenetic proteins (BMPs) in promoting astro-glial differentiation in GBM-derived cells, as shown by increased Smad1/5/8 phosphorylation and increased proportion of $\mathrm{GFAP}^{+}$cells. $^{16,20-23}$ Nevertheless, epigenetic-mediated dysfunction of BMP receptor $1 \mathrm{~B}$ in a subset of GBM tumours represses the pro-differentiative effects of $\mathrm{BMPs},{ }^{24}$ clearly indicating that tumour cells can hamper anti-cancer treatments to varying degrees.

Here, we investigate whether a BMP2-based pro-differentiating treatment increased sensitivity to TMZ in GBM cells derived from the anoxic/hypoxic core, which we found to be the most resistant tumour area to $T M Z$ treatment. Our data indicate that BMP2 raises sensitivity to TMZ in GBM stem cells, which undergo both glial and neuronal differentiation. Moreover, HIF-1 $\alpha$ protein stability is highly compromised by combined BMP2/TMZ treatment; as a consequence, MGMT expression, which we found to be directly regulated by HIF-1 $\alpha$ at the transcriptional level, is down-modulated. In conclusion, we describe for the first time a HIF-1 $\alpha$-dependent direct regulation of MGMT transcription and propose a novel combined approach to impact GBM stem cell phenotype and survival.

\section{Results}

GBM cells from distinct layers of the mass show different tumorigenic potential. We previously found that cells taken from the inner portions of GBM mass, besides expressing CD133 and Nestin at high levels, are more resistant to $\mathrm{TMZ}$ treatment due to high MGMT expression. ${ }^{3}$ To further demonstrate that these cells are the most aggressive in the mass, we took biopsies from the three distinct GBM layers (Figure 1a) and analysed their phenotype (Supplementary Figure S1), confirming previous results. ${ }^{3}$ We then derived cells from each biopsy, cultured as described ${ }^{3,25}$ and then injected them subcutaneously in SCID mice (Figure 1a). Notably, GBM cells from the three layers displayed comparable apoptosis levels before injection (data not shown). Starting from 6 weeks post-injection, only GBM cells derived from the core and the intermediate layer were able to generate tumours in mice (Figure 1b). Moreover, cells derived from the core grew faster than intermediate layer cells, displaying the greatest tumorigenic potential (Figure 1b). GBM cells derived from tumour xenografts displayed different levels of the stemness markers CD133 and Sox2, with core-derived tumours showing the highest percentage of $\mathrm{CD}_{133^{+}}$and $\mathrm{Sox} 2^{+}$ cells (Figure 1c). Immunohistological analyses confirmed these data, revealing that core cells-derived xenografts were characterized by higher levels of Nestin compared with intermediate layer with no significant differences in GFAP or $\beta$-III-tubulin expression (Figures 1d, e). In addition, we evaluated HIF-1 $\alpha$ expression and found it higher in xenograft tumours derived from GBM core cells (Figure 1f). These data validate in vivo our previous assumption on GBM CSC distribution, ${ }^{3}$ showing that core cells in the GBM mass contain the highest amount of CSCs and display the most aggressive phenotype.

BMP2 pre-treatment sensitizes resistant GBM cells to TMZ. We and the others recently reported that BMPs are able to promote astro-glial differentiation of GBM-derived cells and to decrease their $\mathrm{CD}_{133^{+}}$cell fraction, ${ }^{16,20-23}$ As we showed that TMZ induces high levels of apoptosis only in differentiated GBM cells, ${ }^{3}$ we tested whether differentiation induction of CSCs sensitized resistant cells to TMZ.

At first, we tested the phenotypic effects mediated by several pro-differentiating agents on GBM cells derived from the GBM core and confirmed that 5 days of culture in presence of BMP2 was the most effective pro-differentiating treatment compared with other factors and was able to induce both decrease of $\mathrm{Nestin}^{+}$cells and astro-glial commitment (GFAP upregulation; Supplementary Figure S2).

Pre-treatment with BMP2 increased sensitivity to TMZ in resistant GBM cells by significantly reducing the number of cells when combined with TMZ (Figure 2a). Moreover, the proliferation marker Ki67 was significantly downregulated in BMP2/TMZ-treated cells (Figure $2 \mathrm{~b}$ and Supplementary Figure S3A). Cell-cycle analysis conducted on BrdUstained cells suggested that BMP2/TMZ combination induced a reduction of the percentage of cells in G0/G1 and $S$ phase with a concomitant increase in the subGo fraction, representative of dying cells (Supplementary Figure S3B), this hinting the involvement of cell death induction after combined treatment with BMP2 and TMZ. Accordingly, analysis of Annexin V/PI (Annexin V/propidium iodide) revealed a dramatic increase of early apoptotic cells (i.e., Annexin $\mathrm{V}^{+} / \mathrm{PI}^{-}$) only after BMP2/TMZ treatment (Figure 2c).

Interestingly, analyses of CD133 subpopulation in GBM cells derived from the core indicated that BMP2 treatment alone reduced the number of $\mathrm{CD}_{13}{ }^{+}$and the subsequent addition of $\mathrm{TMZ}$ almost abolished $\mathrm{CD} 133^{+}$cells (Figure $2 \mathrm{~d}$ ). In addition, BMP2/TMZ treatment strongly impaired generation of GBM neurospheres (Figure 2e). As a recent work from Beier et $a l^{8}$ suggested that $\mathrm{TMZ}$ was able to target preferentially GBM CSCs, thus reducing their number in the GBM population, we sought to investigate which population (CD133 $^{+}$or $\mathrm{CD}_{133^{-}}$cells) within the core area was mostly affected by BMP2/TMZ combined treatment. Double staining with CD133 and Annexin-V showed that CD133 ${ }^{+}$GBM cells did not undergo apoptosis following either BMP2, TMZ or 
a
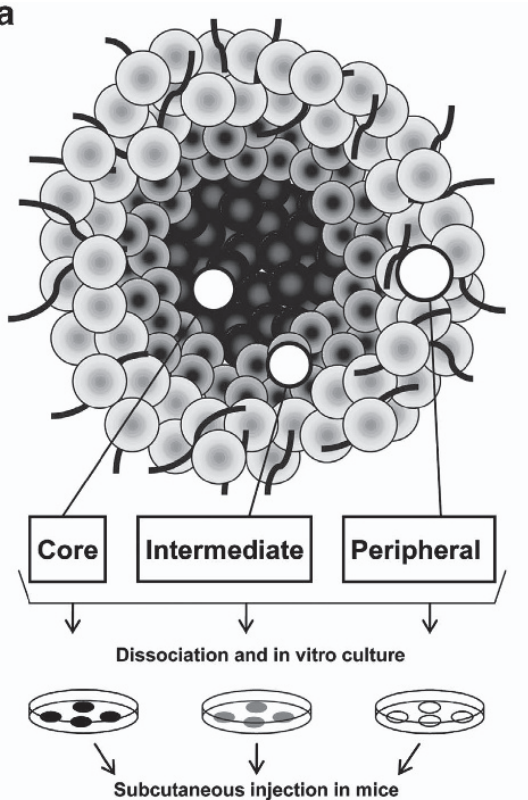
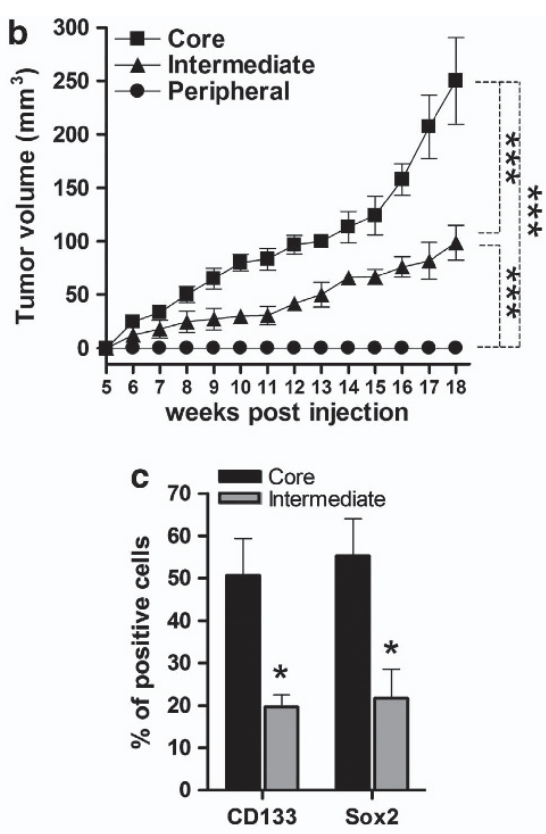
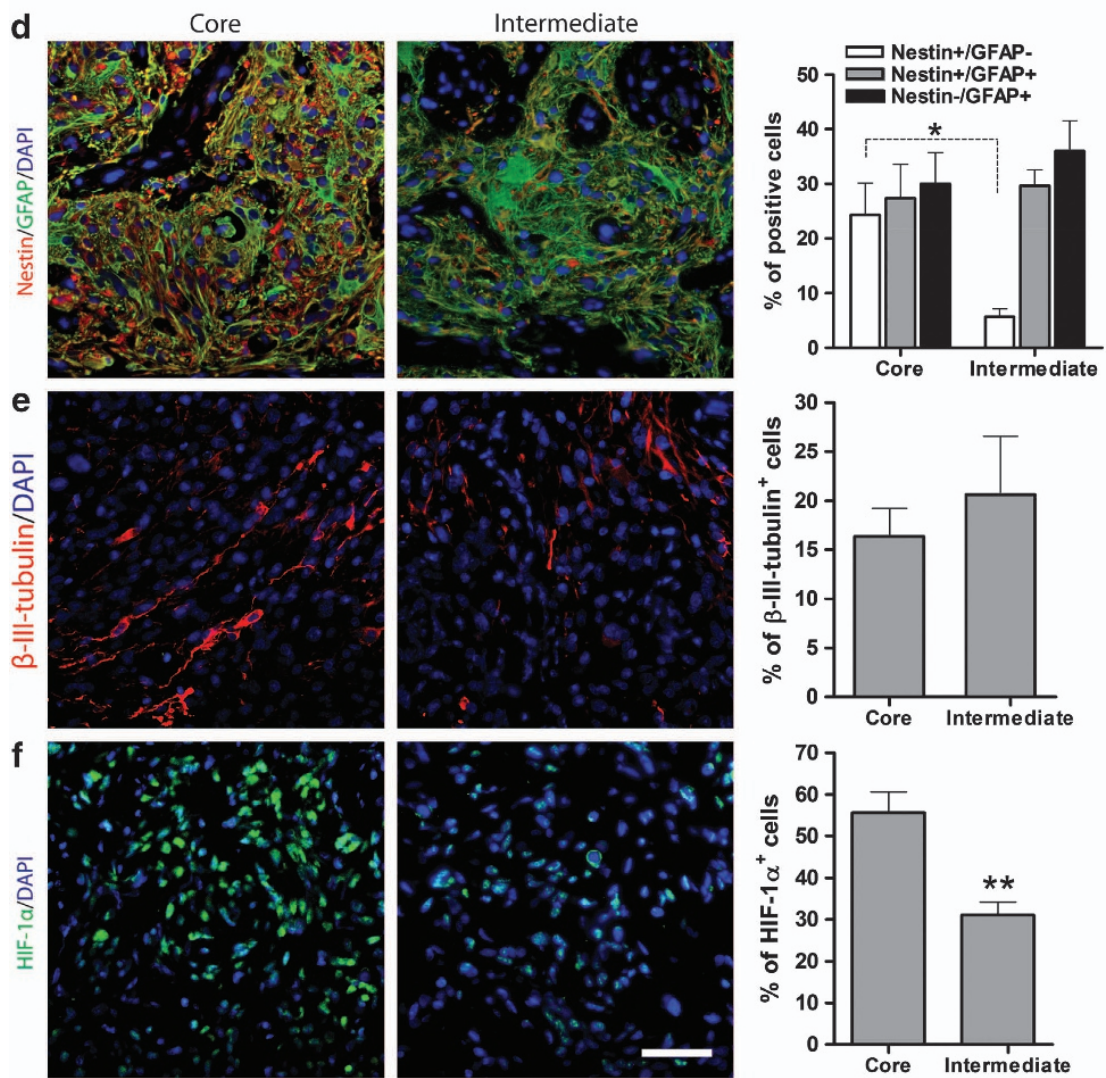

Figure 1 Differential tumorigenic potential of GBM cells from distinct tumour layers. (a) Schematic diagram showing different location from which distinct GBM cells (core, intermediate and peripheral layer cells) were derived. (b) Growth kinetics of GBM cells derived from distinct tumour layers and injected subcutaneously with $2.5 \times 10^{5}$ cells into both dorsolateral flanks in SCID mice. Seven mice per experimental group were used. (c) Cytofluorimetric measurement of CD133 and Sox2 levels in cells derived from GBM xenografts at killing (18 weeks post-injection). (d-f) Images showing phenotypic analysis of GBM xenografts from different GBM layers and relative quantification (right). (d) Nestin (red)/GFAP (green), (e) $\beta$-III-tubulin (red) and (f) HIF-1 $\alpha$ (green) were analysed; bar $=40 \mu \mathrm{M} .{ }^{*} P<0.05,{ }^{* \star} P<0.01,{ }^{* \star *} P<0.001$

BMP2/TMZ treatment, whereas CD133- ${ }^{-}$cells significantly died under the same conditions (Figure 2f). These data suggest that BMP2 pre-treatment, by shifting GBM cells toward a more differentiated phenotype, increases GBM cells sensitivity to $T M Z$, inducing significant apoptosis induction only in more differentiated cells (Figure 2f). 
a
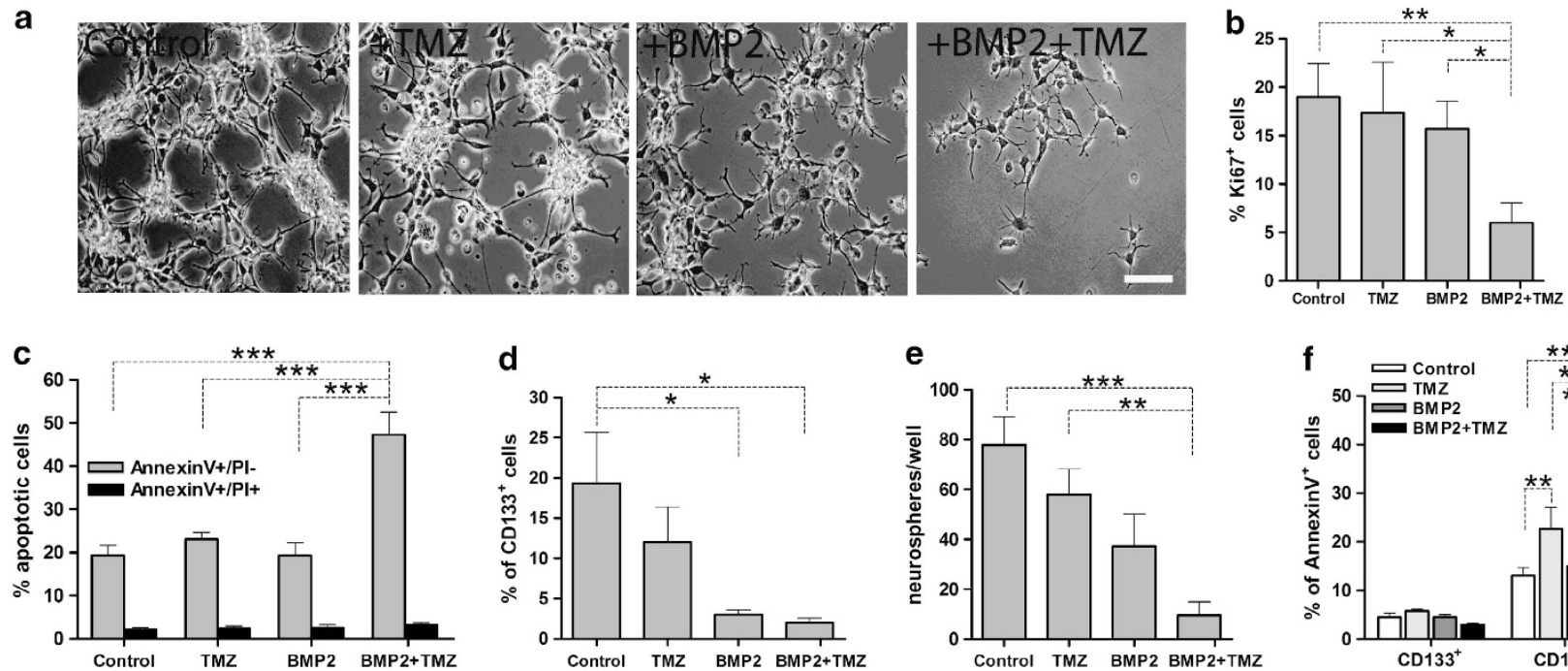

d

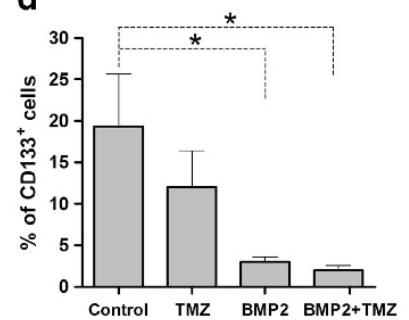

e

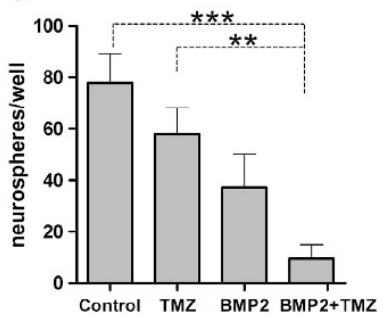

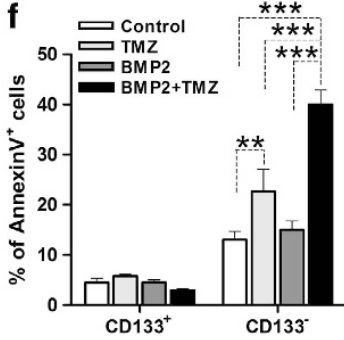

Figure 2 BMP2-pretreated GBM cells derived from the core become sensitive to TMZ. (a) Representative pictures of GBM cells (HuTuP56) derived from the dissociation of the core. GBM cells were plated at medium density $\left(\mathrm{T}_{0}=47 \mathrm{cells} / \mathrm{mm}^{2}\right)$ at $2 \% \mathrm{O}_{2}$. Pictures were taken after 5 days of BMP2 treatment (10 ng $\left./ \mathrm{ml}\right)$ and additional 2 days with or without additional TMZ $(500 \mu \mathrm{M})$. Bar $=40 \mu \mathrm{M}$. (b) Bar graph reporting relative Ki67 $7^{+}$cells quantification. Representative images are reported in Supplementary Figure S3A. (c) Bar graph showing quantification of early apoptotic cells (grey; Annexin $\mathrm{V}^{+} / \mathrm{PI}^{-}$) and late apoptotic cells (black; Annexin $\mathrm{V}^{+} / \mathrm{PI}^{+}$). (d) Histogram resembling percentage of $\mathrm{CD}_{133^{+}}$cells in GBM cells treated as in (a). (e) Histogram resembling number of neurospheres generated from GBM cells treated as in (a) and then plated in non-adherent conditions (1000 cells/well). Data retrieved from six different tumours. (f) Bar graph reporting the quote of apoptotic cells (Annexin $\mathrm{V}^{+}$cells) in the CD133 ${ }^{+}$and $\mathrm{CD} 133^{-}$subpopulations for GBM cells treated as in (a). For all graphs, mean of four tumours \pm S.E.M., $n=1$ for each tumour. ${ }^{*} P<0.05,{ }^{\star \star} P<0.01,{ }^{\star \star \star} P<0.001$

\section{Co-treatment with BMP2 and TMZ induces differentiation} of resistant GBM cells. To better understand the effects mediated by BMP2 and TMZ, we analysed the phenotype of live remaining core cells after treatments. Immunofluorescence on adherent cells showed that BMP2 treatment alone increased the percentage of $\mathrm{GFAP}^{+}$and $\beta$-III-tubulin ${ }^{+}$cells and BMP2/TMZ co-treatment slightly strengthened this effect (Figure $3 a$ and Supplementary Figures S4A-B). Interestingly, TMZ alone significantly augmented the $\beta$-III-tubulin ${ }^{+}$cell population (Figure $3 a$ and Supplementary Figure S4B). We then analysed the expression of additional stemness/differentiation markers, such as Sox2, Oct4, MAP2 and GalC. We found a significant decrease of the stem cell-associated markers Sox2 and Oct4 after TMZ and BMP2 treatments, with the most pronounced effect being mediated by the combination of both (Figure 3a). On the contrary, the differentiation markers MAP2, expressed in mature neurons, and GalC, expressed in mature oligodendrocytes, were mostly upregulated at the same conditions (Figure 3a). These data were confirmed by cytofluorimetric analyses that showed a significant decrease of Sox2 and Nestin following BMP2/TMZ treatment (Figures $3 \mathrm{~b}, \mathrm{c}$ ) and a dramatic increase of GFAP and CD44 levels with a slight reduction of Doublecortin ${ }^{+}$cells (Figures $3 b-c$ ). In particular, GBM cells progressively over-expressed both GFAP and CD44 (Supplementary Figure S5A), with more immature cells $\left(\mathrm{CD}_{133^{+}}\right.$and Sox $\left.{ }^{+}\right)$gradually differentiating to glial lineage (Supplementary Figures S5B-C). Interestingly, proliferating cells $\left({\mathrm{Ki} 67^{+}}^{+}\right.$) were found to co-express Nestin, and BMP2/ TMZ treatment reduced expression of both the markers (Supplementary Figure S5D).

To track the phenotypic changes of $\mathrm{CD} 133^{+}$cells after treatments, core $\mathrm{CD}_{133^{+}}$cells were stained with Dil or DiD membrane-staining dyes after sorting and then re-mixed $1: 10$ with $\mathrm{CD}_{133^{-}}$cells to recreate tumour heterogeneity (Supplementary Figure S6). Cell-tracking experiments confirmed that BMP2, and in particular BMP2/TMZ treatment, induced a significant differentiation of the GBM CSC population (Supplementary Figure S6B-C). Moreover, immunofluorescence analysis on CD133-sorted GBM cells disclosed a significant induction of astro-glial differentiation (loss of Nestin and over-expression of GFAP) exerted by BMP2 and in particular by the BMP2/TMZ co-treatment on $\mathrm{CD}_{133^{+}}$cells (Supplementary Figure S6D; left panel). CD133 ${ }^{-}$cells resulted to be more differentiated, undergoing a dramatic loss of $\mathrm{GFAP}^{+}$and $\beta$-Ill-tubulin ${ }^{+}$cells following $\mathrm{TMZ}$ treatment (alone or in combination with BMP2), probably due to cell death induction of more differentiated CD133 cells (Supplementary Figure S6D; right panel).

BMP2/TMZ combined treatment downregulates HIF-1 $\alpha$ signalling pathway. We previously reported that BMP2 modulate HIF-1 $\alpha$ protein stability and its transcriptional activity in GBM, thus strengthening its pro-differentiation effects. ${ }^{22}$ For this reason, we investigated whether increased sensitivity to TMZ mediated by BMP2 was related to HIF-1 $\alpha$ signalling pathway modulation. We evaluated whether $\mathrm{HIF}-1 \alpha$ activity was compromised in the presence of TMZ and BMP2 and performed transfection of GBM cells derived from either the core or the intermediate area by using a hypoxia-responsive element (HRE)-luciferase reporter construct. We found that TMZ treatment alone did not affect HIF- $1 \alpha$-mediated transcription in GBM cells (Figure $4 a$ ). HIF-1 $\alpha$ activation was slightly impaired by BMP2 alone, whereas pre-treatment with BMP2 and subsequent addition of $\mathrm{TMZ}$ induced a very strong reduction of HRE-luciferase 

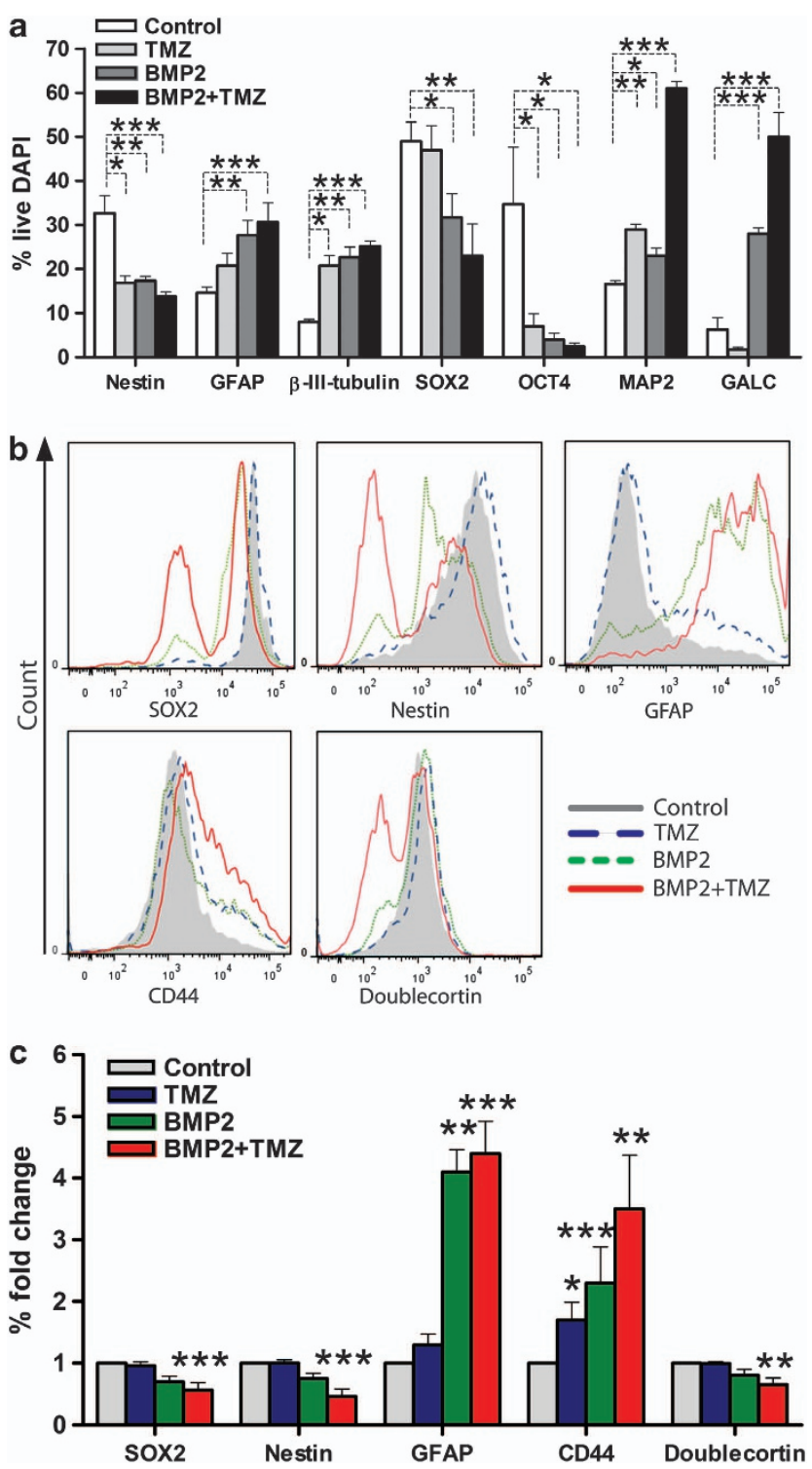

Figure 3 BMP2/TMZ combination promotes differentiation of live remaining GBM cells derived from the core. (a) Bar graph reporting relative Nestin ${ }^{+}, \mathrm{GFAP}^{+}$, $\beta$-IItubulin ${ }^{+}, \mathrm{Sox}^{+}, \mathrm{Oct}^{+}, \mathrm{MAP}^{+}{ }^{+}$and $\mathrm{GalC}^{+}$cell quantification based on percentage of $\mathrm{DAPI}^{+}\left(4^{\prime}, 6\right.$-diamidino-2-phenylindole) cells. GBM cells were plated at medium density $\left(T_{0}=47\right.$ cells $\left./ \mathrm{mm} 2\right)$ and treated with BMP2 and or TMZ. (b) Representative analysis of GBM-derived cells (HuTuP83) treated as described in (a) and stained for various markers of stemness/differentiation according to the BD Stemflow Human Neural Lineage Analysis Kit's instructions. (c) Bar graph reporting percentage of subpopulations showed in (b). Mean of three tumours \pm S.E.M., $n=1$ for each tumour. ${ }^{*} P<0.05,{ }^{* \star} P<0.01,{ }^{* \star *} P<0.001$

signal (Figure 4a). As a confirm, BMP2/TMZ treatment almost abrogated HIF-1 $\alpha$ protein (Figure $4 \mathrm{~b}$ ) and reduced the expression of its downstream target genes vascular endothelial growth factor (VEGF) and carbonic anhydrase 9 (CAIX). ${ }^{26,27}$

We hypothesized that the BMP2/TMZ-dependent HIF-1 $\alpha$ signalling inhibition could be controlled by the HIF- $1 \alpha$ negative regulator proline hydroxylase 2 (PHD2), and we found it upregulated by BMP2 and TMZ (Figure 4b). Moreover, we analysed PHD2 promotorial region and found at least two different binding sites for the BMP intracellular effectors Smad1,5,8 ( -1417 and + 549 bp from the ATG; Figure 4c, upper panel), which have been previously described to be present in the ID1 promoter. ${ }^{28}$ Chromatin immunoprecipitation (ChIP) analysis revealed a direct binding of phosphorylated Smad 1,5,8 on ID1 and PHD2 promoter in both sites after BMP2 stimulus (Figure 4c, bottom panel), suggesting a direct regulation of $\mathrm{PHD} 2$, and consequently $\mathrm{HIF}-1 \alpha$ levels mediated by BMP2.

Besides HIF- $1 \alpha$, HIF- $2 \alpha$ has also been reported to have a fundamental role in mediating the hypoxic response and GBM stem cell regulation. ${ }^{29}$ For this reason, we evaluated whether its levels would be modulated by single and combined treatments. HIF- $2 \alpha$ protein levels did not change after TMZ or BMP2 single treatments, showing a reduction only after BMP2/TMZ combination (Figure 4b). These results indicate that BMP2 makes GBM cells derived from the inner portion of the tumour mass more sensitive to $\mathrm{TMZ}$ treatment and that this effect may be related to decreased protein stability of HIFs.

MGMT expression is dependent on HIF-1 $1 \alpha$. In our previous work, we suggested that MGMT expression might be regulated by $\mathrm{HIF}-1 \alpha{ }^{3}$ Here, we investigated whether MGMT was affected by BMP2 and/or TMZ. MGMT protein expression was downmodulated both by BMP2 and TMZ in GBM cells derived from the inner core, and co-treatment with BMP2 and TMZ further improved this effect (Figure 5a). Analysis of MGMT transcript confirmed its BMP2/TMZmediated downregulation (Figure 5a). As downregulation of HIF- $1 \alpha$ and HIF-2 $\alpha$ occurred following BMP2/TMZ treatment (Figures $4 \mathrm{a}, \mathrm{b}$ ), we tested whether MGMT expression was dependent on HIFs. We performed ChIP analysis on the $10 \mathrm{~kb}$ upstream region of MGMT coding sequence in which we found at least two diverse HREs located at -9050 and $-432 \mathrm{bp}$ from the ATG (Figure 5b). PCR on HIF-1 $\alpha$ - and HIF-2 $\alpha$-immunoprecipitated DNA sequences showed a direct binding of HIFs on the MGMT promoter in hypoxia and that BMP2 almost abrogated HIF-1 $\alpha$, but not HIF-2 $\alpha$, binding to MGMT promoter (Figure 5c). Additional ChIP with RNA polymerase II antibody confirmed impaired transcription of MGMT after BMP2 stimulus (Figure $5 \mathrm{~d}$ ).

To functionally validate the involvement of $\mathrm{HIF}-1 \alpha$ levels in mediating GBM resistance to $\mathrm{TMZ}$, we transduced GBM cells derived from the core with either a HIF- $1 \alpha$-silencing (siHIF- $1 \alpha$ l EGFP (enhanced green fluorescent protein)) or a control vector (siLUC/EGFP) and evaluated the effects driven by HIF- $1 \propto$ suppression on GBM sensitivity to TMZ. Silenced cells underwent HIF-1 $\alpha$ signalling downregulation, with a strong reduction of MGMT levels (Figure 6a). On the contrary, HIF-2 $\alpha$-silenced GBM cells displayed only a slight downmodulation of MGMT protein levels (Figure $6 b$ ), confirming a potential predominant role of $\mathrm{HIF}-1 \alpha$ in the regulation of MGMT transcription. In addition, HIF- $1 \alpha-$, but not HIF- $2 \alpha-$, silenced GBM cells displayed a significant induction of apoptosis when exposed to TMZ, as shown by the increased levels of Annexin $\mathrm{V}^{+} / \mathrm{PI}^{-}$compared with control cells (Figure 6c, d).

To further characterize the role of HIF-1 $\alpha /$ MGMT axis in prompting GBM cell resistance to $\mathrm{TMZ}$ therapy, we 
a

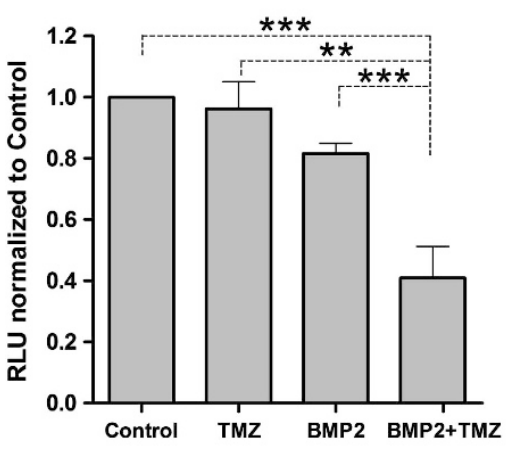

b

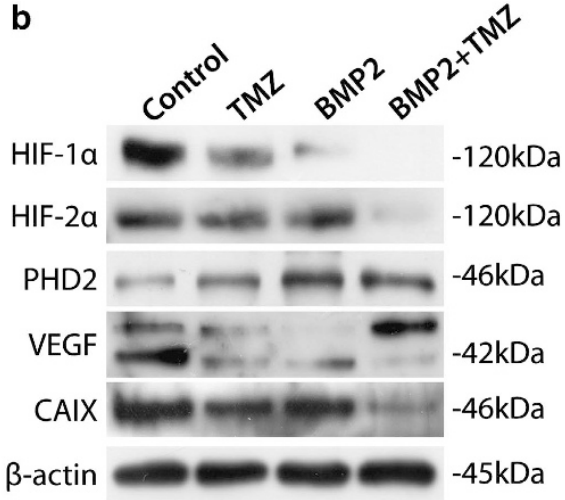

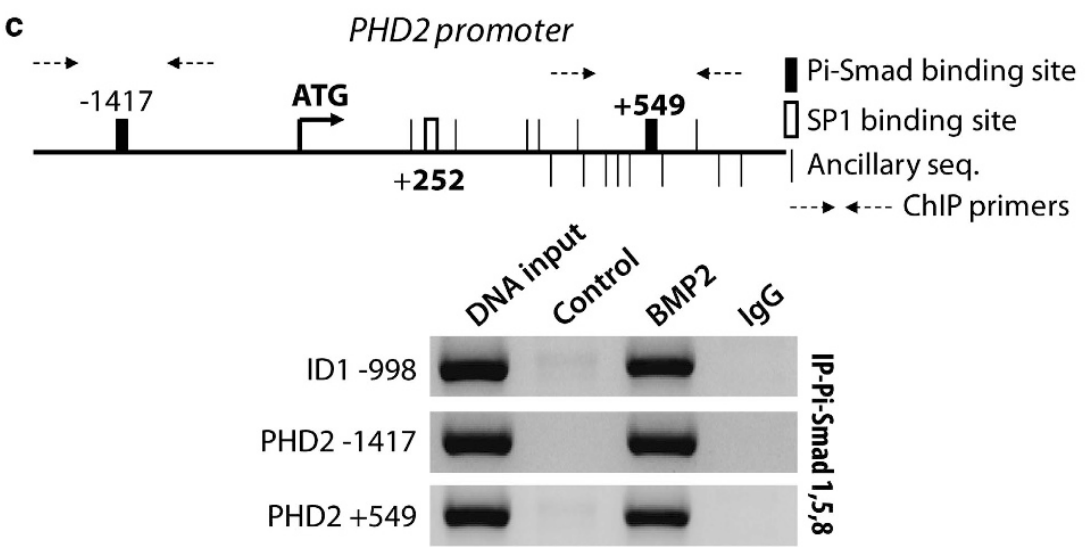

Figure 4 HIF-1 $\alpha$ signalling pathway is downregulated by BMP/TMZ treatment. (a) HRE-luciferase assay. Values are expressed in relative light units (RLU). After transfection, cells were treated with BMP2 (50ng/ml) and/or TMZ $(500 \mu \mathrm{M})$ for $12 \mathrm{~h}$ as described in Materials and Methods. Three different GBM have been analysed, $n=2$ for each tumour. (b) Representative western blot analyses (HuTuP60) of HIF-1 $\alpha$, HIF-2 $\alpha$, PHD2, CAIX, VEGF along with $\beta$-actin to control for protein loading in GBM cells derived from the core and treated as described. The analysis has been confirmed on four additional tumours. (c) Schematic diagram representing PHD2 promoter (upper panel). ChIP analysis for PHD2 promoter performed on 293T cells treated or not with BMP2. DNA sequences were immunoprecipitated by using Pi-SMAD 1,5,8 or an irrelevant antibody (lower panel). ${ }^{\star \star} P<0.01,{ }^{\star \star \star} P<0.001$

transfected TMZ-sensitive GBM cells (derived from the peripheral layers of the tumour $)^{3}$ with a plasmid bearing a truncated sequence of HIF-1 $\alpha$ (Hif- $1 \alpha-\Delta$ ODD) lacking the oxygen-dependent degradation (ODD) domain. This broken form of HIF-1 $\alpha$ has been described not to be controlled by microenvironmental oxygen, thus leading to HIF- $1 \alpha$ signalling over-activation. $^{30} \mathrm{HIF}-1 \alpha-\Delta \mathrm{ODD}$ transfection resulted in $\mathrm{HIF}-1 \alpha$ transcriptional activation even at $20 \%$ oxygen (Figure 6e) and induced over-stabilization of HIF-1 $\alpha-\Delta$ ODD truncated protein $(75 \mathrm{kDa})$ independently of environmental oxygen (Figure 6f). As expected, HIF-1 $\alpha$ full protein was expressed only in hypoxic conditions (110 kDa; Figure 6f). MGMT protein expression was strictly correlated with HIF- $1 \alpha / \mathrm{HIF}-1 \alpha-\Delta$ ODD levels (Figure 6f), confirming the HIF-1 $\alpha$-dependent control of MGMT expression.

We treated peripheral HIF- $1 \alpha-\Delta$ ODD-transfected cells with $\mathrm{TMZ}$ and then evaluated apoptosis induction. As expected, non-transfected (control) cells displayed a strong apoptotic response after TMZ exposure as shown by a dramatic increase of Annexin $\mathrm{V}^{+} / \mathrm{PI}^{-}$cells (Figure $6 \mathrm{~g}$ ). On the contrary, HIF- $1 \alpha-\Delta$ ODD expression made GBM cells more resistant to $\mathrm{TMZ}$ treatment (Figure $6 \mathrm{~g}$ ), thus proving the fundamental role of HIF- $1 \alpha$ and MGMT in supporting GBM cell resistance to $\mathrm{TMZ}$.

\section{Discussion}

GBM is the most common and lethal primary brain tumour, displaying high heterogeneity that renders this tumour class difficult to treat. ${ }^{31}$ The role of GBM CSCs has received much attention than past, especially with regards to their ability of activating pro-survival pathways, repairing DNA damage, and, as recently reported, to sustain tumour angiogenesis by differentiating into vascular structures. ${ }^{7,19,32}$ Furthermore, the decrease in oxygen supply (hypoxia) has been described as one of the major characteristic of the GBM niche, as it is involved in CSCs maintenance and in the regulation of tumour metabolism, proliferation, angiogenesis and resistance to therapies. ${ }^{18,33,34}$

In this study, we investigated the role of BMP2 in increasing sensitivity to $T M Z$ of hypoxic GBM cells (i.e., derived from the core of the tumour mass). We recently reported on the existence of concentrically determined layers within the GBM tumour mass, ${ }^{3,25,35}$ demonstrating that CSCs-enriched GBM cells derived from the inner core of the mass are poorly sensitive to in vitro TMZ treatment. Here we show that cells derived from distinct tumour layers possess a differential tumorigenic potential as shown by growth kinetics of subcutaneous xenografts. The choice of generating flank 
a
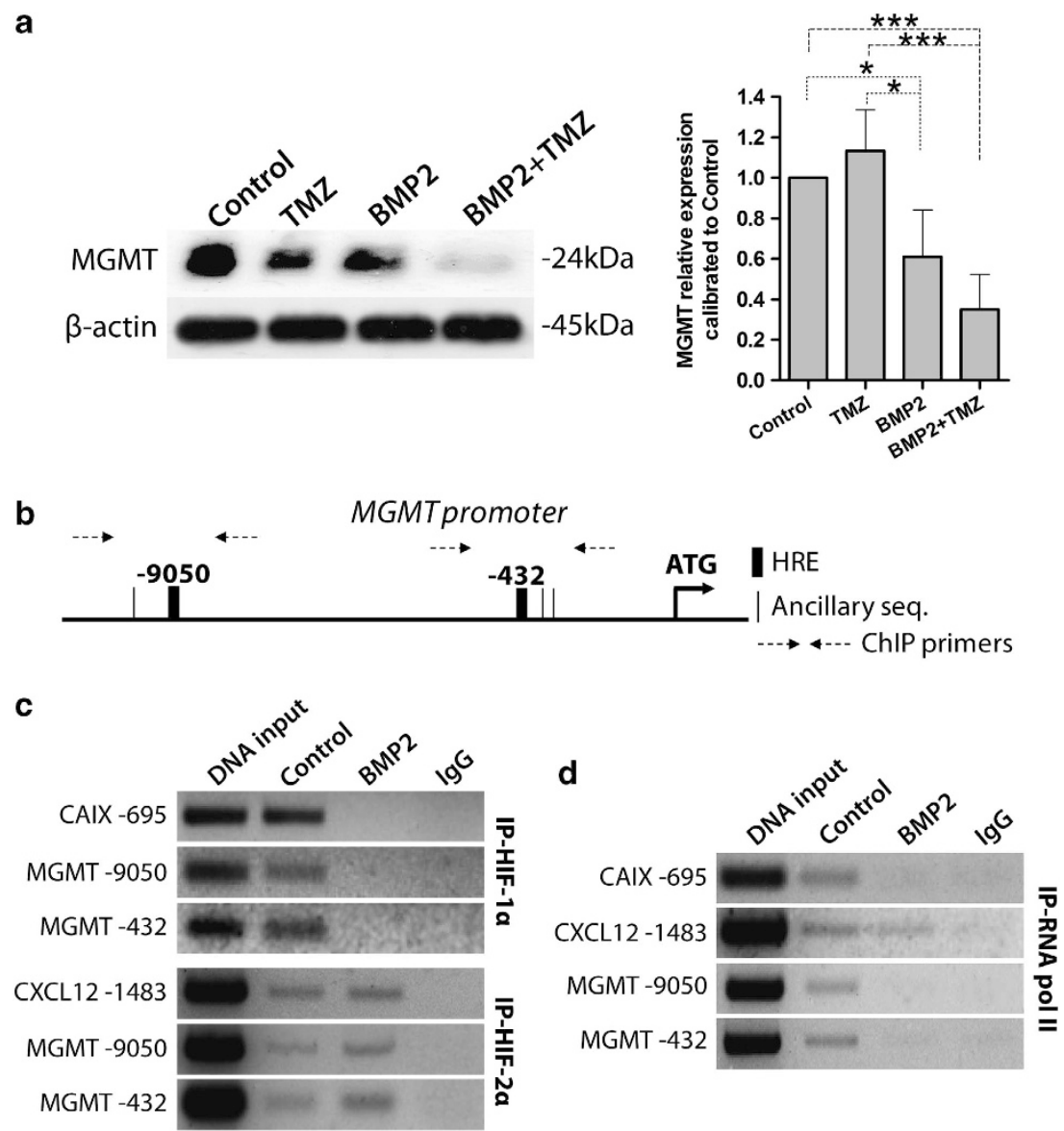

Figure 5 MGMT expression is dependent on HIF-1 $\alpha$. (a, left) Representative western blot analyses (HuTuP60) of MGMT along with $\beta$-actin to control for protein loading in GBM cells derived from the core and treated as described. The analysis has been confirmed on five additional tumours. (Right) Quantitative real-time PCR analysis of MGMT mRNA normalized to GUSB. (b-d) ChIP analysis for MGMT $5^{\prime}$ upstream sequence performed on 293T cells treated or not with BMP2. DNA sequences were immunoprecipitated by using HIF-1 $\alpha$, HIF-2 $\alpha$, RNA polymerase II or an irrelevant antibody. For (a), mean \pm S.E.M. comparing three different GBM, $n=3$ for each tumour. ${ }^{\star} P<0.05,{ }^{* \star *} P<0.001$

tumours was determined as they allow the direct measurement of their volume even though the subcutaneous microenvironment could possibly generate phenotypic artefacts due to the absence of specific signals coming from brain tissues. $^{36}$ GBM xenografts generated from human cells injected in murine brain are known to recapitulate the genetic and phenotypic heterogeneity related to the original GBM biopsies. ${ }^{37}$ Importantly, we found that flank injection of GBM cells derived from the three tumour layers partially recapitulated the GBM tumour mass observed in patient histological samples, and this was reliably due to the intrinsic, diverse phenotypic identity of the three layers-derived transplanted GBM cells.

In this study, BMP2 promoted a strong differentiation of GBM-derived stem-like cells and subsequent addition of TMZ induced a dramatic increase of apoptosis. As BMP2 or TMZ delivered as single treatments did not alter apoptosis level in these cells, ${ }^{16,21,38}$ we argued that BMP2/TMZ combined treatment should impact GBM cells by a synergistic effect.

HIF- $1 \alpha$ expression correlates to maintenance of an immature phenotype in GBM. ${ }^{16}$ Conversely, downregulation of HIF- $1 \alpha$ is known to attenuate human glioma cell growth in vivo, ${ }^{39,40}$ to reduce cell migration and invasion ${ }^{41}$ and is associated to the acquisition of a more committed phenotype. ${ }^{16}$ Indeed, we have previously reported that BMP2 can counteract HIF- $1 \alpha$ stability and its signalling pathway activation by modulating PHD2 and its regulator FKBP38, ${ }^{16,22}$ and here we demonstrate that BMP2 is able to directly regulate PHD2 transcription. In light of these data, we suggest that BMP2 might increase TMZ sensitivity by a dual effect. First, BMPs drive hypoxic-resistant CSCs toward differentiation as shown here and by other studies. ${ }^{16,20,21,23,42}$ Second, BMP2 is able to modulate the expression of PHD2, thus counteracting HIF- $1 \alpha$ stability and its pro-resistance effects.

The DNA repair protein MGMT has a relevant prognostic value in GBM management, as promoter methylation is currently considered a useful biomarker of responsiveness to $\mathrm{TMZ},{ }^{43}$ even if it does not accurately predict MGMT protein expression. ${ }^{9}$ We demonstrated that distinct sensitivity of GBM layers to $\mathrm{TMZ}$ matched the differential expression of MGMT throughout the GBM mass. ${ }^{3}$ Moreover, a previous report from Kitange et al. ${ }^{44}$ demonstrated that MGMT expression levels strictly correlated to $\mathrm{TMZ}$ responsiveness in GBM both in vitro and in vivo. Here, we found a substantial down-modulation of 
a

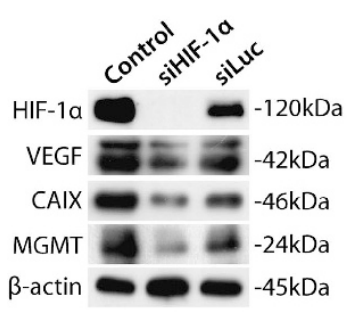

b

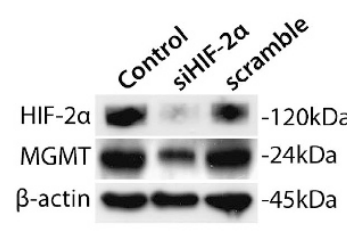

C $\begin{gathered}\text { AnnexinV+/PI- } \\ \text { AnnexinV+/PI+ }\end{gathered}$

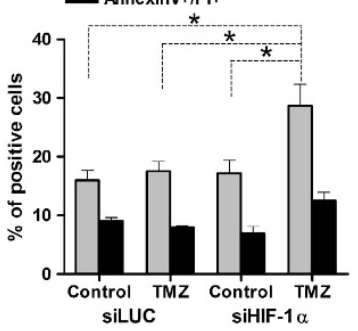

d

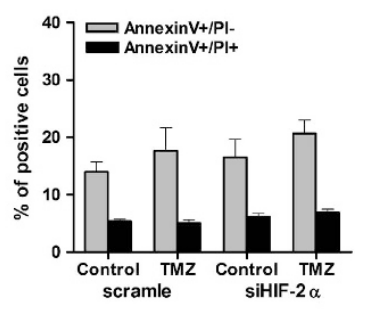

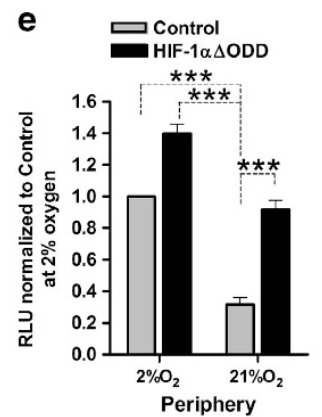
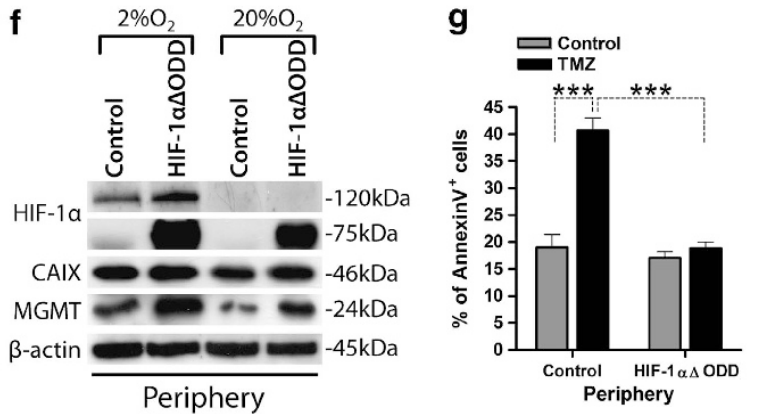

Figure 6 GBM resistance to TMZ is dependent on HIF-1 $\alpha$ and MGMT. ( $\mathbf{a}$ and $\mathbf{b}$ ) Representative western blot analyses of the proteins indicated. Proteins were extracted from GBM cells derived from the core and transduced with a siHIF-1 $\alpha / E G F P$ - or siLUC/EGFP-bearing vectors compared with control group (non-transduced cells; a) or either transfected with a HIF-2 $\alpha$ siRNA or scramble sequences compared with control group (non-transfected cells; $\mathbf{b}$ ). (c and d) Bar graphs showing Annexin V/PI analysis of HIF-1 $\alpha$-silenced (c), HIF-2 $\alpha$-silenced (d) or relative control cells treated or not with TMZ. Mean \pm S.E.M. comparing six different GBM. (e) HRE-luciferase assay. Values are expressed in relative light units (RLU). GBM cells derived from the periphery of the tumour were transfected with HRE-reporter construct and either with a control plasmid or a HIF-1 $\alpha \Delta$ ODD-bearing vector. After $48 \mathrm{~h}$, luciferase activity was analysed. Three different GBM have been analysed, $n=2$ for each tumour. (f) Western blot analysis showing protein expression of HIF-1 $\alpha$ (full protein $110 \mathrm{kD}$; truncated form with $\Delta \mathrm{ODD} 75 \mathrm{kD}$ ), CAIX, MGMT and $\beta$-actin as loading control in HIF- $1 \alpha \Delta \mathrm{ODD}$ or control plasmid transfected cells at 2 or $20 \%$ oxygen tensions. The analysis was repeated on three additional GBM. (g) Bar graph reporting percentages of early apoptotic (Annexin $\mathrm{V}^{+} / \mathrm{PI}^{-}$) peripheral cells transfected with either HIF-1 $\alpha \Delta$ ODD or control plasmid and then treated with TMZ (black bars) or not (grey bars). ${ }^{*} P<0.05,{ }^{* \star *} P<0.001$

MGMT transcription and protein expression after BMP2/TMZ treatment. As both HIF- $1 \alpha$ (Figure 4b) and MGMT (Figure 5a) were found downregulated by BMP2/TMZ treatment, we analysed whether MGMT expression was dependent on HIF- $1 \alpha$ and confirmed this hypothesis by unravelling a specific HIF- $1 \alpha$-mediated direct control of MGMT transcription. This further confirms the role of HIF- $1 \alpha$ in sustaining molecular signalling involved in cancer cell aggressiveness and therapy resistance. A direct regulation of MGMT by HIF- $1 \alpha$ has not been previously described, even though we could not exclude the intervention of other proteins, diverse from MGMT, but regulated by HIF- $1 \alpha$, which could possibly sustain GBM resistance to therapy. Moreover, we have to take into account that MGMT expression could potentially be driven also by other factors, not necessarily correlated to hypoxia.

As previously demonstrated, $\mathrm{HIF}-1 \alpha$ silencing dramatically increases sensitivity to TMZ in vivo. ${ }^{45}$ Accordingly, in our experiments, HIF- $1 \alpha$ suppression promotes down-modulation of MGMT, and this is sufficient to override GBM resistance to TMZ. Interestingly, HIF-2 $\alpha$ has been described to be equally important in the hypoxic response and GBM stem cell regulation, ${ }^{29}$ but in our experimental setting, it appears to be only partially involved in MGMT regulation and TMZ treatment response.

Data presented here add details on the molecular mechanisms by which HIF- $1 \alpha$ contributes to tumour resistance to therapy and how pro-resistant factors, such as MGMT, are regulated. By using BMP2, we induced a strong differentiation of GBM CSCs. In parallel to this, the decrease of HIF- $1 \alpha$ stability and, consequentially, of MGMT expression, increased sensitization of cells to TMZ. In addition, we suggest that MGMT is one of the genes activated by HIF- $1 \alpha$, but not HIF-2 $\alpha$, at the transcriptional level within the GBM hypoxic core. We describe a potential approach to more effectively target TMZ-resistant CSCs within the GBM mass that could be exploited to create newly synthesized molecules, possibly designed to mimic BMP2 binding to its receptors, or other factors able to stimulate GBM CSC differentiation along with HIF- $1 \alpha$ or MGMT levels downmodulation. ${ }^{46,47}$ These data suggest that GBM cell pretreatment with pro-differentiating agents and/or molecules able to regulate HIF- $1 \alpha$ levels may more effectively target the resistant CSC population when combined with alkylating drugs.

\section{Materials and Methods}

Neurosurgical sample collection, isolation and gas-controlled expansion of GBM cells. Written informed consent for the donation of adult tumour brain tissues was obtained from patients before tissue acquisition under the auspices of the protocol for the acquisition of human brain tissues obtained from the Ethical Committee of the Padova University Hospital. All tissues were acquired following the tenets of the Declaration of Helsinki. GBM cells were derived from 10 tumours taken at surgery (Supplementary Table S1). Through radiological imaging, three layers were identified in the GBM mass, classified as core, intermediate layer and peripheral/hyper-vascularized tumour area, as previously described ${ }^{3,25}$ (Figure 1a). The tumour inner cores of the tumours were partially necrotic, ranging from 10 to $45 \%$ of total area (data not shown). We enzymatically dissociated the three layers separately and cultured derived cells in HAM'SF12/DME (Irvine Scientific, Santa Ana, CA, USA) with additional BIT9500 
(10\%, serum substitute, Stem Cell Technologies, Vancouver, Canada), $20 \mathrm{ng} / \mathrm{ml}$ basic fibroblast growth factor and $20 \mathrm{ng} / \mathrm{ml}$ epidermal growth factor (both human and from R\&D Systems, Minneapolis, MN, USA), in an atmosphere of $2 \%$ oxygen, $5 \%$ carbon dioxide and the balance nitrogen as previously described. ${ }^{16,22}$ For continuous expansion, half of the medium was replaced every day, and cultures were passaged for no more than 3 consecutive passages in order to avoid longterm culture-related effects.

In some experiments, GBM cells derived from the core and the intermediate layer were treated either with TMZ ( $500 \mu \mathrm{M}$; Sigma-Aldrich, St. Louis, MO, USA) used alone for $48 \mathrm{~h}$ or added following 5 days of incubation with BMP2 $(10 \mathrm{ng} / \mathrm{ml}$, Immunological Sciences, Rome, Italy). Concentration of TMZ was set based on the half-maximal inhibitory concentration (IC50) as previously reported. ${ }^{3,8}$ To test the pro-differentiating effects on GBM cells derived from the core and from the intermediate layer, cyliary neurotrophic factor $(10 \mathrm{ng} / \mathrm{ml}, \mathrm{R} \& D$ Systems), B27 (1:50, Gibco, Carlsbad, CA, USA), Neurotrophin-3 (10 ng/ml, R\&D Systems), foetal bovine serum (1\%, Gibco) and $\mathrm{LiCl}_{2}(1 \mathrm{mM}$, Sigma-Aldrich) were added either alone or combined as indicated in Supplementary Figure S2.

In some experiments, GBM cells derived from the peripheral layers of the mass were transfected using a protocol for transient transfection of adherent cells with Effectene reagent (Qiagen, Hilden, Germany) with a pcDNA3.1 backbone bearing a truncated sequence of the HIF- $1 \alpha$ transcript named HIF- $1 \alpha-\Delta \mathrm{ODD}$ or a control pcDNA3.1 empty plasmid. HIF- $1 \alpha-\Delta O D D$ sequence encodes a stabilized form of HIF- $1 \alpha$, lacking the oxygen-sensitive degradation (ODD) domain. ${ }^{30}$ After $48 \mathrm{~h}$ from transfection, GBM cells were exposed to TMZ as described above, and then we evaluated their HIF-1 $\alpha$ transcriptional activity, used them either for western blot analyses or for measuring apoptosis induction.

Tumorigenicity assay. SCID mice were purchased from Charles River (Wilmington, MA, USA). Procedures involving animals and their care conformed with institutional guidelines that comply with national and international laws and policies (EEC Council Directive 86/609, OJ L 358, 12 December, 1987). Six- to ten-week-old male mice were used for experiments. For tumour establishment, GBM cells derived from the three identified tumour layers were washed and diluted in serum-free DME-F12. Mice were injected subcutaneously with $2.5 \times 10^{5}$ cells in a $200-\mu \mathrm{l}$ total volume into both dorsolateral flanks. Cells were injected in combination with additional $200 \mu$ l of Matrigel (Becton Dickinson, Franklin Lakes, NY, USA). The resulting tumours were inspected weekly and measured by caliper; tumour volume was calculated with the following formula: tumour volume $\left(\mathrm{mm}^{3}\right)=L \times I^{2} \times 0.5$, where $L$ is the longest diameter, $I$ is the shortest diameter and 0.5 is a constant to calculate the volume of an ellipsoid. After tumour formation, animals were killed, tumour mass was excised and dissociated to either single-cell suspension for cytofluorimetric analyses or was formalin-fixed and paraffin-embedded with standard procedures for histology.

Immunofluorescence. Human and xenograft biopsies were paraffinembedded and cut in $5-\mu \mathrm{M}$-thick sections. A number of sections was used for hematoxylin and eosin staining, others for immunofluorescence analyses. For this purpose, sections were re-hydrated and then antigen retrieval was performed by incubation with citrate buffer $0.01 \mathrm{M} \mathrm{pH} 6$ at $95{ }^{\circ} \mathrm{C}$ for $20 \mathrm{~min}$. After saturation with $5 \%$ BSA, slides were incubated with Nestin (mouse, 1:200, Millipore, Billerica, MA, USA), glial fibrillary acidic protein (GFAP, rabbit, 1:1000, Dako, Glostrup, Denmark), $\beta$-IIItubulin (Tuj-1, mouse, 1:500, Covance, Princeton, NJ, USA) and HIF-1 $\alpha$ (rabbit, 1:100, Sigma-Aldrich Prestige, St. Louis, MO, USA). Adherent cells were fixed in cold $4 \%$ paraformaldehyde for $15 \mathrm{~min}$, rinsed and stored before analysis. Primary antibody staining was performed for Nestin, GFAP, $\beta$-III-tubulin (1:1000), Ki67 (mouse, 1:100, Dako), Sox2 (1: 100; Cell Signalling Technologies, Beverly, MA, usa), Oct4 (1:50; ProteinTech Group, Chicago, IL, USA), MAP2 (1:100; Sigma-Aldrich) and GalC (Chemicon, Billerica, MA, USA). After incubation with primary antibodies, in both protocols cells were washed and incubated with species-specific secondary antibodies conjugated to Alexa dyes (1:1000, Invitrogen, Carlsbad, CA, USA) and counterstained with DAPI (4',6-diamidino-2-phenylindole; 1:10000, Sigma-Aldrich). Stainings were visualized by epifluorescence (Vico, Nikon, Melville, NY, USA).

Cytofluorimetric analyses and cell sorting. Cells $\left(2 \times 10^{5} \mathrm{cells} / \mathrm{ml}\right)$ were incubated with anti-human CD133 (clone AC133/2-PE, Miltenyi Biotec, Bergisch Gladbach, Germany) as previously described. ${ }^{16,22}$ Viability was assessed by adding 7-amino-actinomycin-D ( $50 \mathrm{ng} / \mathrm{ml}$, BD Biosciences, Franklin Lakes, $\mathrm{NJ}$, USA) before analysis. Analysis of apoptosis was performed as recommended using the Annexin Fluo kit (Roche Diagnostics, Basel, Switzerland). Cell-cycle analysis with BrdU (Roche Diagnostics) was performed according to the manufacturer's instructions. BrdU was incubated with cells for $12 \mathrm{~h}$. Analysis of cell phenotype and differentiation was achieved by using the Stemflow Neural Cell Lineage Kit (Becton Dickinson) according to the manufacturer's instructions.

GBM cells stained with Annexin V/PI or BrDU were analysed on a Cytomics FC500 flow cytometer (Beckman Coulter, Brea, CA, usa). GBM cells stained for stemness/differentiation markers were acquired with a BD Facs Aria III (Becton Dickinson). Relative percentages of different subpopulations were calculated based on live gated cells (as indicated by physical parameters, side scatter and forward scatter). Unlabelled cells and cells incubated with appropriate isotypic control antibodies were first acquired to ensure labelling specificity.

For cell sorting experiments, cells were analysed on a BD Facs Aria III (Becton Dickinson) and then sorted on the basis of CD133 expression. Cell fractions of interest were selected by setting appropriate sorting gates. Cells to be sorted were resuspended in complete medium and kept cold until sorting. Sorted cells were collected in a tube containing growth medium and checked for the purity of populations before their use.

To track phenotypic changes of $\mathrm{CD} 133^{+}$cells after treatments, GBM cells were stained for CD133, sorted and then labelled with membrane-staining dyes (Dil or DiD; Invitrogen). Sorted and labelled cells were then used to generate mixed population containing $\mathrm{CD}_{133^{+}} / \mathrm{Di}^{+}$cells and $\mathrm{CD} 133^{-}$cells subjected to $\mathrm{TMZ}$ and/ or BMP2 treatments as described in Supplementary Figure S6. Analysis of cell phenotype and differentiation was measured by using the Stemflow Neural Cell Lineage Kit (Becton Dickinson) on Di-labelled (CSCs) gated GBM cells.

HRE-luciferase reporter assay. GBM cells derived from the core and from the intermediate layer were transfected using a protocol for transient transfection of adherent cells using Effectene reagent (Qiagen). HRE-luciferase reporter construct was used (WHRE). It consists of a trimerized 24-mer containing $18 \mathrm{bp}$ of sequence from the PGK promoter including the HRE $\left(5^{\prime}\right.$-tgtcacgtcctgcacgactctagt- $3^{\prime}, \mathrm{HRE}$ ) and an $8 \mathrm{bp}$ linker sequence followed by a $50 \mathrm{bp}$ minimal tyrosine kinase promoter in a pGL2-firefly luciferase basic Vector backbone (Promega, Madison, WI). The mutant HRE (mHRE) construct, used to evaluate non-specific effects, has the ACG of the HIF-1 binding site mutated to CAT, which abolishes binding, as well as a point mutation that eliminated a Bsgl restriction site for diagnostic purposes. GBM cells were transfected alternatively with wHRE or mHRE luciferase reporter plasmids. Transfection with a Renilla luciferase vector was used in order to normalize luciferase detection (Promega). Twelve hours after transfection, a total medium change was done and cells were treated with $500 \mu \mathrm{M}$ of TMZ alone, $50 \mathrm{ng} / \mathrm{ml}$ of BMP2 or a combination of both for $24 \mathrm{~h}$. Cells were processed for analysis of HRE-luciferase activity as described (Dual-Luciferase Reporter Assay System, Promega) using a plate-reading luminometer (Victor, Perkin Elmer, Milano, Italy). The values reported in the graphs are expressed in relative light units and were normalized to the control group at $2 \%$ oxygen.

Western blot. Total protein extracts were isolated in lysis buffer. Equal amounts of protein $(10 \mu \mathrm{g})$ were resolved using a SDS-PAGE gels and transferred to PVDF Hybond-p membrane (GE Healthcare, London, Canada). Membranes were blocked with ECL Advance Blocking (2\%, Amersham Pharmacia, London, Canada) overnight, under rotation at $4{ }^{\circ} \mathrm{C}$. Membranes were then incubated with primary antibodies against HIF- $1 \alpha$ (mouse, 1:500; BD Biosciences), HIF- $2 \alpha$ (mouse, 1:1000; Novus Biologicals, Littleton, CO, USA), PHD2 (rabbit, 1:1000; Novus Biologicals), VEGF (rabbit, 1:500; Santa Cruz Biotechnology, Santa Cruz, CA, USA), CAIX (mouse, 1:2000; Novus Biologicals), MGMT (mouse, 1:1000, Novus Biologicals) and $\beta$-actin (mouse, 1:10000, Sigma-Aldrich) for $2 \mathrm{~h}$. Membranes were next incubated with peroxidase-labelled goat anti-rabbit or anti-mouse IgG (1:50000, Sigma-Aldrich) for $60 \mathrm{~min}$. All membranes were visualized using ECL Advance (GE Healthcare) and exposed to Hyperfilm MP (GE Healthcare).

Quantitative real-time PCR analysis. For analysis of gene expression, RNA was isolated from cells using Trizol (Invitrogen) and $0.5 \mu \mathrm{g}$ of total RNA reverse-transcribed using SuperScript RNAse HReverse Transcriptase (Invitrogen). Quantitative real-time PCR reactions were run in triplicate using Brilliant SYBR Green QPCR Core Reagent Kit (Stratagene, La Jolla, CA, USA). Fluorescent emission was recorded in real-time (Sequence Detection System $7900 \mathrm{HT}$, Applied Biosystems, Carlsbad, CA, USA). Gene expression profiling was completed using the comparative $\mathrm{Ct}$ method of relative quantification. PCR amplification conditions consisted of 40 cycles with primers annealing at $60^{\circ} \mathrm{C}$. 
Primers specific for beta-glucuronidase (GUSB) (101 bp, F:5'-GAAAA TACGTGGTTGGAGAGCTCATT-3'; R:5'-CCGAGTGAAGATCCCCTTTTTA-3') and MGMT (199 bp, F:5'-ATGGATGTTTGAGCGACACA-3'; R:5'-ATAGAGCA AGGGCAGCGTTA- $3^{\prime}$ ) have been designed using the software Primer 3 (http:// frodo.wi.mit.edu/primer3/input.htm) and the specificity of the primers sequences was evaluated using the software Human BLAT Search (http://genome.ucsc.edu/ cgi-bin/hgBlat?command=start). Relative RNA quantities were normalized to GUSB as housekeeping gene and $2 \%$ oxygen, untreated group (control $2 \%$ oxygen), was used as the calibrating condition ( $\Delta \Delta \mathrm{Ct}$ Method).

ChIP assay. We performed CHIP assay on 293T cells cultured in DMEM (Euroclone S.p.A., Milan, Italy) with additional 10\% foetal bovine serum (Gibco, Invitrogen) and maintained in hypoxic conditions $\left(2 \% \mathrm{O}_{2}\right)$. Cells were exposed to $20 \mathrm{ng} / \mathrm{ml}$ of soluble BMP2 for $48 \mathrm{~h}$ or maintained in DMEM $10 \%$ foetal bovine serum. Collected cells were sonicated $30 \mathrm{sec} \times 8$ times in water bath sonicator and immunoprecipitation was performed by using anti-Pi-Smad 1,5,8 (Cell Signalling Technologies), anti-HIF-1 $\alpha$ (AbCam, Cambridge, UK), anti-HIF-2 $\alpha$ (Novus Biologicals) and anti-RNA polymerase II (Santa Cruz Biotechnology) antibody. Purification of genomic DNA (immunoprecipitated and DNA input samples) was performed by phenol/chloroform extraction. We detected specific promoter sequences from IgG irrelevant antibodies (negative control) or specific antibodies immunoprecipitated DNAs and DNA input (positive control) samples by PCR using $2 \mu$ of each DNA sample obtained after extraction. Primer sequences used were: ID1-998 forward: 5'-GTTGGGAGACTCGCAGGTGT-3' and reverse: 5'-CCTGAACCTGCAACAGTTCG-3'; PHD2-1417 forward: 5'-CAAGCCTAGC ACCCCACTTTC-3' and reverse: 5'-GTGCTGCGCGGATGAATACAAT-3'; PHD2 + 549 forward: $5^{\prime}$-CTCATCGCTGTTCCAGGAGAA-3' and reverse: $5^{\prime}$-CACAGAT GCCGTGCTTGTTCAT-3'; CAIX - 695 forward: $5^{\prime}$-AGGTCTCTTGGGCAA GGTTT-3' and reverse: 5'-TCCTGCTCAAAAGCCTTCAT-3'; CXCL12-1483 forward: $5^{\prime}$-TCTAACGGCCAAAGTGGTTT-3' and reverse: $5^{\prime}$-GCCACCT CTCTGTGTCCTTC-3'; MGMT - 9050 forward: 5'-GATCAGGAAAAATGAGGTG GAAA- $3^{\prime}$ and reverse: $5^{\prime}$-TGCTTTGCCATTTGTGAACTG-3'; and MGMT - 432 forward: 5'-TGACAGGGTCTCTGCTGGTC-3' and reverse: 5'-GCGCCCGCTTAGT GAGAAT- 3 '. Primers have been designed as described above.

Transduction of GBM-derived cells using lentiviral vectors. Lentiviral plasmids containing HIF- $1 \alpha$ siRNA and LUC siRNA target sequences and a GFP expression cassette, termed pLSLG-HIF- $1 \alpha$-siRNA and pLSLGLuciferase-siRNA, respectively, were a kind gift of Dr. O.V. Razorenova (Department of Molecular Cardiology, Lerner Research Institute, Cleveland, OH, USA). ${ }^{48}$ The lentiviral vectors were produced as previously described ${ }^{16}$ and used to infect GBM cells. Target GBM cells were incubated with vector supernatants for at least $12 \mathrm{~h}$. Transduction efficiency was determined by the measurement of GFP + cells by flow cytometry (FC500 Beckman Coulter). Transduced cells were cultured for 2 days before proteins were extracted and analysed by western blot. In some experiments, cells were transduced and, after 2 days of culture, treated with TMZ for $48 \mathrm{~h}$ and stained with Annexin V/PI.

Statistical analysis. Graphs and statistical analyses were prepared using Prism 3.03 (GraphPad, La Jolla, CA, USA). All values are presented as mean \pm standard error of the mean (S.E.M.). Statistical significance was measured by one-way ANOVA with Newman-Keuls multiple comparison posttest and paired $t$-test; ${ }^{*} P<0.05,{ }^{\star *} P<0.01,{ }^{* \star *} P<0.001$. For all graphs, asterisks over brackets indicate a significant difference with another variable as indicated and asterisks over bars indicate a significant difference with the control group.

\section{Conflict of Interest}

The authors declare no conflict of interest.

Acknowledgements. We thank Dr. OV Razorenova (Department of Molecular Cardiology, Lerner Research Institute, Cleveland, $\mathrm{OH}$ ) for providing pLSLG-HIF- $1 \alpha$-siRNA and pLSLG-LuciferasesiRNA. pHIF- $1 \alpha-\Delta$ ODD plasmid was kindly gifted by Professor JA Hubbell (Integrative Biosciences Institute, Ecole Polytechnique Fédérale de Lausanne (EPFL), Lausanne, Switzerland). Also, we are grateful to Dr. M Montagner (Department of Biomedical Sciences, University of Padova, Padova, Italy) for providing HIF-2 $\alpha$ siRNAs and technical help in ChIP procedures and Dr. G Nardo (Istituto Oncologico Veneto-IRCCS, Padova, Italy) for help in animal handling. This work was supported by funds from Fondazione Città della Speranza (to CF), the Italian Association for the Fight against Neuroblastoma (Pensiero Project; to FP), the Italian Association for Cancer Research-AIRC (Interregional paediatric project grant; to GB), University of Padova-Young Investigators Grant 2010 (to LP) and University of Padova-Progetto d'Ateneo 2010 (to SI). ER was supported by a fellowship from AIRC.

1. Villano JL, Seery TE, Bressler LR. Temozolomide in malignant gliomas: current use and future targets. Cancer Chemother Pharmacol 2009; 64: 647-655.

2. Liu G, Yuan X, Zeng Z, Tunici P, Ng H, Abdulkadir IR et al. Analysis of gene expression and chemoresistance of CD133 + cancer stem cells in glioblastoma. Mol Cancer 2006; 5: 67.

3. Pistollato F, Abbadi S, Rampazzo E, Persano L, Della Puppa A, Frasson C et al. Intratumoral hypoxic gradient drives stem cells distribution and MGMT expression in glioblastoma. Stem Cells 2010; 28: 851-862.

4. Chinot OL, Barrie M, Fuentes S, Eudes N, Lancelot S, Metellus $P$ et al. Correlation between 06-methylguanine-DNA methyltransferase and survival in inoperable newly diagnosed glioblastoma patients treated with neoadjuvant temozolomide. J Clin Oncol 2007; 25: 1470-1475.

5. Hegi ME, Liu L, Herman JG, Stupp R, Wick W, Weller M et al. Correlation of O6-methylguanine methyltransferase (MGMT) promoter methylation with clinical outcomes in glioblastoma and clinical strategies to modulate MGMT activity. J Clin Oncol 2008; 26: 4189-4199.

6. Altaner C. Glioblastoma and stem cells. Neoplasma 2008; 55: 369-374.

7. Sanchez-Martin M. Brain tumour stem cells: implications for cancer therapy and regenerative medicine. Curr Stem Cell Res Ther 2008; 3: 197-207.

8. Beier D, Rohrl S, Pillai DR, Schwarz S, Kunz-Schughart LA, Leukel P et al. Temozolomide preferentially depletes cancer stem cells in glioblastoma. Cancer Res 2008; 68: 5706-5715.

9. Cao VT, Jung TY, Jung S, Jin SG, Moon KS, Kim IY et al. The correlation and prognostic significance of MGMT promoter methylation and MGMT protein in glioblastomas. Neurosurgery 2009; 65: 866-875; discussion 875.

10. Della Puppa A, Persano L, Masi G, Rampazzo E, Sinigaglia A, Pistollato F et al. MGMT expression and promoter methylation status may depend on the site of surgical sample collection within glioblastoma: a possible pitfall in stratification of patients? J Neurooncol 2011; 106: 33-41.

11. Quillien V, Lavenu A, Karayan-Tapon L, Carpentier C, Labussiere M, Lesimple T et al. Comparative assessment of 5 methods (methylation-specific polymerase chain reaction, methylight, pyrosequencing, methylation-sensitive high-resolution melting, and immunohistochemistry) to analyze 06-methylguanine-DNA-methyltranferase in a series of 100 glioblastoma patients. Cancer 2012; 118: 4201-4211.

12. Calabrese C, Poppleton H, Kocak M, Hogg TL, Fuller C, Hamner B et al. A perivascular niche for brain tumor stem cells. Cancer Cell 2007; 11: 69-82.

13. Gilbertson RJ, Rich JN. Making a tumour's bed: glioblastoma stem cells and the vascular niche. Nat Rev Cancer 2007; 7: 733-736.

14. Heddleston JM, Li Z, Lathia JD, Bao S, Hjelmeland AB, Rich JN. Hypoxia inducible factors in cancer stem cells. Br J Cancer 2010; 102: 789-795.

15. Heddleston JM, Li Z, McLendon RE, Hjelmeland AB, Rich JN. The hypoxic microenvironment maintains glioblastoma stem cells and promotes reprogramming towards a cancer stem cell phenotype. Cell Cycle 2009; 8: 3274-3284.

16. Pistollato $F$, Chen HL, Rood BR, Zhang HZ, D'Avella D, Denaro $L$ et al. Hypoxia and HIF1alpha repress the differentiative effects of BMPs in high-grade glioma. Stem Cells 2009; 27: 7-17.

17. Pistollato F, Chen HL, Schwartz PH, Basso G, Panchision DM. Oxygen tension controls the expansion of human CNS precursors and the generation of astrocytes and oligodendrocytes. Mol Cell Neurosci 2007; 35: 424-435.

18. Li Z, Bao S, Wu Q, Wang H, Eyler C, Sathornsumetee S et al. Hypoxia-inducible factors regulate tumorigenic capacity of glioma stem cells. Cancer Cell 2009; 15: 501-513.

19. Amberger-Murphy V. Hypoxia helps glioma to fight therapy. Curr Cancer Drug Targets 2009; 9: 381-390.

20. Chirasani SR, Sternjak A, Wend P, Momma S, Campos B, Herrmann IM et al. Bone morphogenetic protein-7 release from endogenous neural precursor cells suppresses the tumourigenicity of stem-like glioblastoma cells. Brain 2010; 133(Pt 7): 1961-1972.

21. Piccirillo SG, Reynolds BA, Zanetti N, Lamorte G, Binda E, Broggi G et al. Bone morphogenetic proteins inhibit the tumorigenic potential of human brain tumour-initiating cells. Nature 2006; 444: 761-765.

22. Pistollato F, Rampazzo E, Abbadi S, Della Puppa A, Scienza R, D'Avella D et al. Molecular mechanisms of HIF-1alpha modulation induced by oxygen tension and BMP2 in glioblastoma derived cells. PLoS One 2009; 4: e6206.

23. Tate CM, Pallini R, Ricci-Vitiani L, Dowless M, Shiyanova T, D'Alessandris GQ et al. A BMP7 variant inhibits the tumorigenic potential of glioblastoma stem-like cells. Cell Death Differ 2012; 19: 1644-1654.

24. Lee J, Son MJ, Woolard K, Donin NM, Li A, Cheng CH et al. Epigenetic-mediated dysfunction of the bone morphogenetic protein pathway inhibits differentiation of glioblastoma-initiating cells. Cancer Cell 2008; 13: 69-80. 
25. Pistollato F, Persano L, Puppa AD, Rampazzo E, Basso G. Isolation and expansion of regionally defined human glioblastoma cells in vitro. Curr Protoc Stem Cell Biol 2011; Chapter 3: Unit 3.4.

26. Fedele AO, Whitelaw ML, Peet DJ. Regulation of gene expression by the hypoxia-inducible factors. Mol Interv 2002; 2: 229-243.

27. Liao SY, Lerman MI, Stanbridge EJ. Expression of transmembrane carbonic anhydrases, CAIX and CAXII, in human development. BMC Dev Biol 2009; 9: 22

28. Lopez-Rovira T, Chalaux E, Massague J, Rosa JL, Ventura F. Direct binding of Smad1 and Smad4 to two distinct motifs mediates bone morphogenetic protein-specific transcriptional activation of Id1 gene. J Biol Chem 2002; 277: 3176-3185

29. Seidel S, Garvalov BK, Wirta V, von Stechow L, Schanzer A, Meletis K et al. A hypoxic niche regulates glioblastoma stem cells through hypoxia inducible factor 2 alpha. Brain 2010; 133(Pt 4): 983-995.

30. Trentin D, Hall H, Wechsler S, Hubbell JA. Peptide-matrix-mediated gene transfer of an oxygen-insensitive hypoxia-inducible factor-1alpha variant for local induction of angiogenesis. Proc Natl Acad Sci USA 2006; 103: 2506-2511.

31. Salacz ME, Watson KR, Schomas DA. Glioblastoma: Part I. Current state of affairs. Mo Med 2011; 108: 187-194.

32. Wang R, Chadalavada K, Wilshire J, Kowalik U, Hovinga KE, Geber A et al. Glioblastoma stem-like cells give rise to tumour endothelium. Nature 2010; 468: 829-833.

33. Jogi A, Ora I, Nilsson H, Lindeheim A, Makino Y, Poellinger L et al. Hypoxia alters gene expression in human neuroblastoma cells toward an immature and neural crest-like phenotype. Proc Natl Acad Sci USA 2002; 99: 7021-7026.

34. Wong ET, Brem S. Antiangiogenesis treatment for glioblastoma multiforme: challenges and opportunities. J Natl Compr Canc Netw 2008; 6: 515-522.

35. Persano L, Rampazzo E, Della Puppa A, Pistollato F, Basso G. The three-layer concentric model of glioblastoma: cancer stem cells, microenvironmental regulation, and therapeutic implications. ScientificWorldJournal 2011; 11: 1829-1841.

36. Reynolds CP, Sun BC, DeClerck YA, Moats RA. Assessing growth and response to therapy in murine tumor models. Methods Mol Med 2005; 111: 335-350.

37. Wakimoto H, Mohapatra G, Kanai R, Curry Jr WT, Yip S, Nitta M et al. Maintenance of primary tumor phenotype and genotype in glioblastoma stem cells. Neuro-oncol 2012; 14: 132-144.

38. Hallahan AR, Pritchard JI, Chandraratna RA, Ellenbogen RG, Geyer JR, Overland RP et al. BMP-2 mediates retinoid-induced apoptosis in medulloblastoma cells through a paracrine effect. Nat Med 2003; 9: 1033-1038.
39. Gillespie DL, Whang K, Ragel BT, Flynn JR, Kelly DA, Jensen RL. Silencing of hypoxia inducible factor-1alpha by RNA interference attenuates human glioma cell growth in vivo. Clin Cancer Res 2007; 13: 2441-2448.

40. Jensen RL, Ragel BT, Whang K, Gillespie D. Inhibition of hypoxia inducible factor-1alpha (HIF-1alpha) decreases vascular endothelial growth factor (VEGF) secretion and tumor growth in malignant gliomas. J Neurooncol 2006; 78: 233-247.

41. Fujiwara S, Nakagawa K, Harada H, Nagato S, Furukawa K, Teraoka M et al. Silencing hypoxia-inducible factor-1alpha inhibits cell migration and invasion under hypoxic environment in malignant gliomas. Int J Oncol 2007; 30: 793-802.

42. Zhou Z, Sun L, Wang Y, Wu Z, Geng J, Miu W et al. Bone morphogenetic protein 4 inhibits cell proliferation and induces apoptosis in glioma stem cells. Cancer Biother Radiopharm 2011; 26: 77-83.

43. Stupp R, Hegi ME. Methylguanine methyltransferase testing in glioblastoma: when and how? J Clin Oncol 2007; 25: 1459-1460.

44. Kitange GJ, Carlson BL, Schroeder MA, Grogan PT, Lamont JD, Decker PA et al. Induction of MGMT expression is associated with temozolomide resistance in glioblastoma xenografts. Neuro-oncol 2009; 11: 281-291.

45. Li L, Lin X, Shoemaker AR, Albert DH, Fesik SW, Shen Y. Hypoxia-inducible factor-1 inhibition in combination with temozolomide treatment exhibits robust antitumor efficacy in vivo. Clin Cancer Res 2006; 12: 4747-4754.

46. Barliya T, Mandel M, Livnat T, Weinberger D, Lavie G. Degradation of HIF-1alpha under hypoxia combined with induction of $\mathrm{Hsp} 90$ polyubiquitination in cancer cells by hypericin: a unique cancer therapy. PLoS One 2012; 6: e22849.

47. Huang $\mathrm{H}$, Lin $\mathrm{H}$, Zhang $\mathrm{X}$, Li J. Resveratrol reverses temozolomide resistance by downregulation of MGMT in T98G glioblastoma cells by the NF-kappaB-dependent pathway. Oncol Rep 2012; 27: 2050-2056.

48. Razorenova OV, Ivanov AV, Budanov AV, Chumakov PM. Virus-based reporter systems for monitoring transcriptional activity of hypoxia-inducible factor 1. Gene 2005; 350: 89-98. published by Nature Publishing Group. This work is licensed under the Creative Commons Attribution-NonCommercial-No Derivative Works 3.0 Unported License. To view a copy of this license, visit http://creativecommons.org/licenses/by-nc-nd/3.0/

\section{Supplementary Information accompanies the paper on Cell Death and Disease website (http://www.nature.com/cddis)}

